\title{
A LOOK AT SOURCES OF ETF UNDERPERFORMANCE: IS THE FOX GUARDING THE HENHOUSE?
}

Frank S. Smith, Colorado State University, Fort Collins, Colorado, USA

Mike Casey, University of Central Arkansas, Conway, Arkansas, USA

dx.doi.org/10.18374/JIFS-14-1.4

\begin{abstract}
Utilizing the largest sample of U.S. equity-based exchange traded funds (ETFs), our analysis confirmed that the annual total performance of ETFs is inferior to the performance of mutual funds across a wide spectrum of investment categories. The average underperformance of 385 basis points per year is not due to previously noted variables, but is strongly related to the daily volatility of ETFs. The main source of this underperformance stems from either the trading process (i.e., authorized participants arbitraging away the returns) or a systematic underperformance of the individuals who manage the funds themselves.
\end{abstract}

Keywords: Exchange Traded Funds, ETFs, Underperformance, Authorized Participants 